\title{
HOST-PARASITE INTERFACE BETWEEN ASELLUS AQUATICUS (ISOPODA) AND LARVAE OF ACANTHOCEPHALUS ANGUILLAE (ACANTHOCEPHALA)
}

\author{
Bahram Sayyaf Dezfuli
}

Department of Biology, University of Ferrara, Via Borsari, 46, 44100 Ferrara, Italy

The present study describes the ultrastructure of the interface between naturally infected isopods, Asellus aquaticus (L.), from the River Brenta (northern Italy) and larvae of Acanthocephalus anguillae (Müller, 1780) Lühe, 1911. A fully developed larva of this helminth occupies the host's hemocoel and induces displacement of its internal organs. A transparent acellular envelope ranging in thickness from 1.1 to $1.6 \mu \mathrm{m}$ covers each $A$. anguillae larva within the hemocoel of the crustacean. This envelope establishes intimate contact with the internal organs and hemocytes of the host. Intact isopod hemocytes, as well as cells in varying degrees of degeneration, were observed mainly on the outermost edge of the envelope of $A$. anguillae. No melanised acanthocephalan larvae were seen within the hemocoel.

The first record of an intermediate host of Acanthocephalus anguillae in Italy was that by Dezfuli et al. (Dezfuli B.S., Rossetti E., Fano E., Rossi R. 1994a: Boll. Zool. 61: 7781). Acanthocephalan larvae can induce a variety of effects on crustacean intermediate hosts. In isopods, these effects include changes in crustacean reproduction (Oetinger D.F. 1987: Trans. Am. Microsc. Soc. 106: 240-248), behaviour (Camp J.W., Huizinga H.W. 1979: J. Parasitol. 65: 667-669) and alterations of isopod secondary sexual characteristics (Munro W. R. 1953: Nature 172: 313; Dezfuli et al. 1994a, op. cit.). Within the hemocoel of the arthropod intermediate host, larval stages of acanthocephalans are surrounded by an envelope. The origin of this envelope has been the subject of controversy (Wanson W.W., Nickol B.B. 1973: J. Parasitol. 59: 1147). The envelope is likely to protect the developing larva from cellular responses of the host. Parasites of invertebrates have become adapted to evade a host's internal defence system (Loker E.S. 1994: J. Parasitol. 88: 728-747).

Specimens of Asellus aquaticus were collected on five occasions from the River Brenta (Italy), and methods were reported in Dezfuli et al. 1994a (op. cit.). Fifty-two specimens of A. aquaticus infected with Acanthocephalus anguillae were recovered. From these, 20 individuals were prepared for transmission electron microscopy according to the methods previously described (Dezfuli et al. 1994a, op. cit.).

Among 52 parasitised isopods, 4 were infected with 2 larvae of A. anguillae each, whereas the other 48 harboured only one larva each. Almost all acanthocephalan larvae were well-developed cystacanths (Fig. 1). The larval stage was identified on the basis of parasite dimensions, shape and development of internal organs, as well as by comparison with larval stages in other acanthocephalan species reported in the literature.

Parasite cystacanths occupied the body cavity of isopods, thus inducing displacement of internal organs, mainly the alimentary tract (Fig. 1) and its associated digestive caeca. Often the cystacanth induced not only displacement of the isopod digestive tract but also a constriction of the intestinal and digestive caeca lumen (Fig. 1). Observations by electron microscopy of the interface between a parasite and its host's digestive tract did not reveal any apparent damage to the isopod alimentary canal.

Each parasite larva was surrounded by a thin acellular envelope (Fig. 2); thickness ranged from 1.1 to $1.6 \mu \mathrm{m}$. The envelope of $A$. anguillae had two distinct parts, the inner part (toward the tegument surface) was electron-dense and formed mainly by filamentous materials, whereas the outer part was moderately electron-dense and formed by granular and filamentous materials (Fig. 2). Moreover, vesiculate profiles with different shapes occurred within the outer part. Some of these were oval to spherical vesicles, and each had a cavity apparently filled with an electron-dense or electron-lucent matrix with diameters ranging from 0.1 to $0.3 \mu \mathrm{m}$. Around the larva, most often the envelope detached from the surface of the parasite tegument (Fig. 2). Light and transmission electron microscopic observations of the envelope of $A$. anguillae in some infected isopods revealed the occurrence of breaks along the length of the envelope. Hemocytes appeared sparsely (Fig. 2) or in clumps (Fig. 3) around the acanthocephalan larva. Depending on the quantity of the granules within the cytoplasm of these cells and their ultrastructural features (Barracco M.A., Amirante G.A. 1992: J. Crustacean Biol. 12: 372-382) three types of hemocytes were recognised around the larvae of $A$. anguillae, namely granular (Figs. 2, 3), semigranular, and hyaline. In many instances host hemocytes were observed to be in contact with the external surface of the cystacanth envelope (Fig. 2). The disintegration of hemocytes was documented as follows. One pole of the hemocyte plasmalemma started to enlarge and thus formed a sort of "vacuole" (Fig. 4a). Then, part of the hemocyte contents migrated into the "vacuole". At some points the plasmalemma which surrounds the "vacuole" broke down and in this way the contents discharged into the isopod's hemocoelic space near the acanthocephalan larval envelope (Fig. 4b).

Like most other groups of arthropods, crustaceans are able to form a multilayered hemocytic capsule that surrounds 

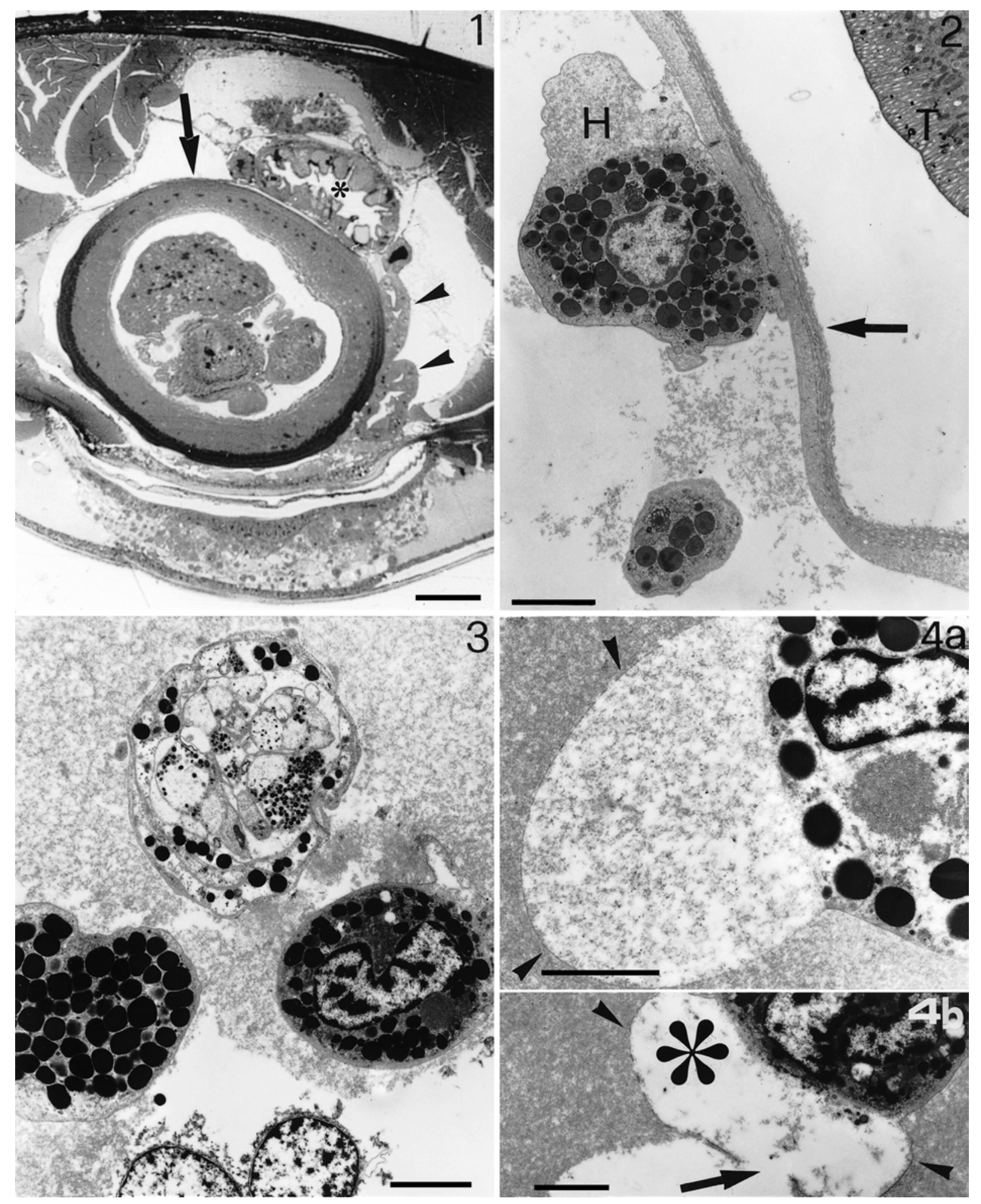

Figs. 1-4. Host-parasite interface between Asellus aquaticus and cystacanth of Acanthocephalus anguillae. Light (Fig. 1) and transmission electron (Figs. 2-4) micrographs. Fig. 1. Note the space occupied by the cystacanth of parasite (arrow) and displacement from the central position of the hindgut (asterisk) and two digestive caeca (arrowheads) to the side of the crustacean body. Fig. 2. Contact between one isopod hemocyte (granulocyte) and parasite envelope (arrow). H -- hemocyte; T parasite tegument. Fig. 3. Occurrence of hemocytes in a clump near the acanthocephalan larva. Fig. 4a. A vacuole is formed by enlargement of the hemocyte plasmalemma (arrowheads). Fig. 4b. Contents of the hemocyte discharged into the vacuole (asterisk), arrow shows the interruption of the plasmalemma (arrowheads). Scale bars: Fig. $1=100 \mu \mathrm{m}$; Figs. $2,3=3 \mu \mathrm{m}$; Figs. $4 \mathrm{a}, 4 \mathrm{~b}=2 \mu \mathrm{m}$. 
macroscopic parasites and pathogens (Loker E.S. 1994, op. cit.). The congregation of arthropod hemocytes around the foreign body is one of the first host responses to an invading organism (Robinson E.S., Strickland B.C. 1969: Exp. Parasitol. 26: 384-392); therefore a probable protective function against the host's cellular response has been attributed to the envelope which surrounds acanthocephalan larvae (Rotheram S., Crompton D.W.T. 1972: Parasitology 64: 15-21). Moreover, this function was confirmed by evidence from transplantation, cytochemical and biochemical investigations (Lackie A.M., Holt R.H.F. 1988: Parasitology 98: 307-314). Observations of infected isopods revealed that the cystacanths of $A$. anguillae were surrounded by some isopod hemocytes. These cells adhered to the outer surface of the parasite's envelope and in many instances partially or completely disintegrated hemocytes were noticed; moreover, no melanised larvae of $A$. anguillae were encountered. In similar studies, the lack of melanised larvae of Moniliformis dubius was assumed to be due to the presence of the envelope around the parasite (Lackie J.M., Rotheram S. 1972: Parasitology 65: 303-308). A. anguillae represents the group of acanthocephalan species with four-layered shells around the parasite eggs, as probably in all species of Acanthocephala; some of these layers persist as an envelope covering the larva (Wanson and Nickol 1973, op. cit.). In a previous study the presence of this envelope was noticed around acanthor, acanthella and cystacanth stages of $A$. anguillae isolated from isopods (Dezfuli et al. 1994a, op. cit.). The origin of the envelope around the larvae of acanthocephalan species has long been the object of controversy. Some authors have attributed the origin of the

Received 11 October 1999 envelope to the arthropod's intestinal tissue (Crompton D.W.T. 1964: Parasitology 54: 721-735) or to the host's hemocytes (Mercer E.H., Nicholas W.L. 1967: Parasitology 57: 169-174) or a combination of both. Other investigators concluded that the envelope is formed wholly by the parasite (Moore D.V. 1962: J. Parasitol. 48: 76-86). More recent observations by transmission electron microscopy attributed part, or most, of the layer components to the acanthocephalan larva, and the residues of host tissues could contribute to increasing its thickness (Lackie and Rotheram 1972, op. cit.; Nikishin V.P. 1992: J. Parasitol. 78: 127-137; Dezfuli B.S., Giari L. 1999: Folia Parasitol. 46: 117-122). The results of the present investigation agree with those of the last-mentioned authors; namely, the envelope around a larva of $A$. anguillae appears to be formed by the parasite tissues. This conclusion was confirmed by ultrastructural comparisons carried out on larvae of other acanthocephalan species (Dezfuli B.S., Bosi G., Rossi R. 1994b: Trans. Am. Microsc. Soc. 113: 34-42).

As reported here, A. anguillae induced displacement of the isopod's alimentary canal and digestive caeca. The same finding was reported in Asellus intermedius infected with Acanthocephalus dirus (Oetinger D.F., Nickol B.B. 1981: J. Parasitol. 67: 672-684) and in specimens of Hyalella azteca (Amphipoda) experimentally infected with Leptorhynchoides thecatus (Spaeth F.W. 1951: J. Morphol. 88: 361-383). According to Spaeth, the larvae of the parasite interfered with the host's metabolism; Spaeth's suggestion might also hold true for infected isopods.

Acknowledgement. I thank William J. Poly from Southern Illinois University for revising the English of the manuscript. 